\title{
Secondary Multiplication of Somatic Embryos in Banana (Musa Spp. AAA) In Semisolid Medium: Effect of the Culture Vessel Type And Sterilization Method
}

\author{
Maritza Reyes Vega ${ }^{1}$, Leonardo Julio Moreno Bermudez ${ }^{1}$, Dion D. Daniels ${ }^{2}$ and Rafael \\ Gómez-Kosky ${ }^{*}$
}

${ }^{1}$ Instituto de Biotecnología de las Plantas (IBP) Universidad Central "Marta Abreu" de Las Villas (UCLV), Carretera a Camajuaní km 5.5 Santa Clara, Villa Clara. CP 54830, Cuba.

* Corresponding Author

2. University of Belice,Belmopan, Belice.

\section{ABSTRACT}

kosky@ibp.co.cu

gomezkosky08@yahoo.es

The objective of this work was to evaluate the influence of the type of culture vessel, and sterilization method on secondary multiplication of somatic embryos of the banana cultivar Grande naine (AAA) in semisolid culture medium. From $200 \mu \mathrm{l}$ of embryogenic cell aggregates, somatic embryos in the globular stage were formed, which were used in the experiments to compare the types of culture vessel (glass and plastic) and the form of sterilization - humid heat (autoclave) and chemical (Vitrofural $\left.{ }^{\circledR}\right)$. The evaluations of the number of somatic embryos that were multiplied were done at 15 and 20 days of culture. The results obtained with respect to the multiplication phase were highly promising, 40.25 and $80.15 \pm 5.0$ somatic embryos at 15 and 20 days of culture in glass vessel with plastic cover and using the autoclave as the sterilization method. The results presented in this work open the door for the use of this phase in the mass propagation protocol of this crop via somatic embryogenesis.

Keywords: Somatic embryogenesis, Musa, Plant tissue culture, Type of vessel, Vitrofural.

\section{Council for Innovative Research}

\author{
Peer Review Research Publishing System
}

\section{Journal: JOURNAL OF ADVANCES IN BIOTECHNOLOGY}

Vol . 4, No. 2.

www.ciribt.org , jbteditor@gmail.com 


\section{INTRODUCTION}

Bananas and plantains, which belong to the genus Musa of the family Musaceae, are widely distributed and constitute a staple food for more than 400 million people around the world. It is cultivated in more than 130 countries in tropical and subtropical regions in almost 10 million hectares with an annual production of 129 million tons (FAOSTAT 2013).

The protocol for scaling up in Cuban commercial laboratories (biofactories) of the somatic embryogenesis technology in bananas and plantains started with the formation of somatic embryos on semisolid culture medium. These were from embryogenic cell aggregates cultured constantly on an orbital shaker and subsequently their maturation, germination and growth to obtain complete plants. However, the true multiplication phase, which is secondary multiplication, has not yet been developed.

The use of this phase in the process of propagation in vitro is of great importance because of the unlimited potential of the secondary multiplication and the recurrence of somatic embryos. Though, the main disadvantage lies in the asynchronism of the process, given the presence of different stages of ontogenic development. The synchronization of the process would avoid the operations of selection of the somatic embryos with adequate characteristics for subsequent maturation, germination and conversion of plants ex vitro(Tonon et al., 2001; Barry-Etienne et al., 2002; Celestino et al., 2005).

Secondary somatic embryogenesis in banana (Musa spp.) has been reported by authors like Escalant et al. (1994) and Gomez-Kosky et al. (2002) in liquid culture medium. The first authors used the temporary immersion systems RITA and the second authors used orbital shakers and bioreactors. This process involves the induction of new somatic embryos from similar preexisting structures (Khalil et al., 2002). Hence, secondary somatic embryogenesis has the potential for the micropropagation of plants, over a long period of time, since the new somatic embryos are formed continuously from preexisting embryos.

The process of somatic embryogenesis is particularly sensitive to the composition of the internal atmosphere during in vitro culture. The use of culture vessels and covers that permit high aeration of the culture can lead to better results during development and maturation of the somatic embryos (Berardi and Marino, 1998).

The chemical 1-(5-bromo-fur-2-il)-2 bromo-2 nitroethene, commercially known as Vitrofural (®), is an antimicrobial compound developed in Cuba. It has a wide spectrum of action against fungi and bacteria. This product has had a therapeutic effect (Blondeauet al., 1999) and has allow the substitution of the autoclave in the sterilization of culture medium used for the micropropagation of banana, plantain, potato and sugarcane (Agramonte et al., 1997). However, this product has never been used in the culture medium in the process of obtaining plants via somatic embryogenesis.

The characteristics of the culture vessel influence the growth and development of explants in plant tissue culture both in semisolid and liquid culture media (Tisserat and Silman, 2000; Chen, 2004; Duetz and Witholt, 2004; Huang and Chen, 2005; Jeonget al.,2006). The importance of the characteristics of the culture vessel has been ignored in many studies, even though authors have indicated differences in the unexpected results obtained when the inoculum and culture medium were used (Lowe et al., 2003). All this previously mentioned has been done for shoot tip culture and in vitro plants via organogenesis; however, for somatic embryogenesis in general, very little works exist and specifically in the secondary multiplication phase of banana. This work is the first report carried out up to this moment on this important phase of somatic embryogenesis.

\section{MATERIALS AND METHODS}

\section{Plant Material}

Male inflorescences from the banana cultivar Grande naine (AAA) were used. The male inflorescences were collected from plants growing in the fields after the emission of the last female flower.

Groups of immature male flowers were extracted for the formation of callus with embryogenic structures following the procedures described by Escalantet al. (1994) for this cultivar. The somatic embryos obtained from the callus were observed after six months of culture and these were used for the establishment of embryogenic cell suspension (ECS).

\section{Establishment of Embryogenic Cell Suspension}

One hundred and fifty milligrams $(150 \mathrm{mg})$ of fresh mass of somatic embryos obtained from callus cultures were inoculated in Erlenmeyer flask (25 mL volumetric capacity), which contained $3.0 \mathrm{ml}$ liquid culture media proposed by Escalantet al. (1994). This was composed of the salts and vitamins proposed by Murashige and Skoog (1962) (MS), 0.5 mg. $\mathrm{L}^{-1}$ biotin, $100 \mathrm{mg} \cdot \mathrm{L}^{-1}$ L-glutamine, $100 \mathrm{mg} \cdot \mathrm{L}^{-1}$ malt extract, $4.5 \mu \mathrm{M}$ 2,4-diclorophenoxyacetic acid (2,4-D), 45 g. $\mathrm{L}^{-1}$ sucrose and the $\mathrm{pH}$ was adjusted to 5.8 prior to autoclaving at $1.1 \mathrm{~kg} . \mathrm{cm}^{-2}$ and $121^{\circ} \mathrm{C}$ for 20 minutes. After 30 days of culture, the ECS were sieved with filters of metallic mesh of $0.5 \mathrm{~mm}$ pore length. The multiplication of the embryogenic cell aggregates less than $0.5 \mathrm{mmwas}$ done adding $1.0 \mathrm{~mL}$ of the sedimented cell volume in Erlenmeyer of $250 \mathrm{~mL}$ volumetric capacity with $30 \mathrm{ml}$ of culture media. After five (5) subcultures, which were done every 30 days, the ECS were used for the formation of somatic embryos in liquid culture medium.

\section{Formation of Somatic Embryos}

From $200 \mu \mathrm{l}$ of embryogenic cell aggregates, somatic embryos in the globular stage were formed on semisolid culture medium. The culture medium used was composed of $100 \% \mathrm{SH}$ inorganic salts (Schenk and Hildebrandt, 1972) supplemented with $100 \% \mathrm{MS}$ vitamins, $1.0 \mathrm{mg} \cdot \mathrm{L}^{-1}$ biotin, $100 \mathrm{mg} \cdot \mathrm{L}^{-1} \mathrm{malt}$ extract, $100 \mathrm{mg} \cdot \mathrm{L}^{-1} \mathrm{~L}-\mathrm{glutamine}, 230 \mathrm{mg} \cdot \mathrm{L}^{-1} \mathrm{~L}-$ 
proline, $10 \mathrm{mg} \cdot \mathrm{L}^{-1}$ lactose, $0.23 \mu \mathrm{Mzeatin}, 100 \mathrm{mg} \cdot \mathrm{L}^{-1}$ myo-inositol, $1.08 \mu \mathrm{M}$ naphthalene acetic acid (NAA), $0.98 \mu \mathrm{M}$ of isopenylaminopurine (2ip), $0.46 \mu \mathrm{M}$ kinetin, $45 \mathrm{~g} . \mathrm{L}^{-1}$ sucrose and gelled with $2.3 \mathrm{~g} . \mathrm{L}^{-1}$ of Gelrite® (Duchefa Co.). The pH was adjusted to 5.3 prior to sterilization. The culture was maintained in conditions of total darkness and at a temperature of $27 \pm 2.0^{\circ} \mathrm{C}$.

\section{SECONDARY OR REPETITIVE MULTIPLICATION}

\section{Effect of the Type of Culture Vessel and the Method of Sterilization}

The somatic embryos formed at 30 days of culture were used in the experiments where the two types of culture vessels were compared: translucent glass vessel with plastic cover (polycarbonate) of $250 \mathrm{ml}$ volumetric capacity (type 1) and vessel completely made of plastic (polycarbonate) of $280 \mathrm{ml}$ volumetric capacity (type 2), (Figure 1) and two forms of sterilization, humid heat (autoclave) and chemical (Vitrofural ${ }^{\circledR}$ ). To both types of vessels, $30 \mathrm{ml}$ of culture media were added for the secondary multiplication of the somatic embryos. The culture medium was composed of MS salts and vitamins and supplemented with $0.5 \mathrm{mg} . \mathrm{L}^{-1}$ biotin, $100 \mathrm{mg} \cdot \mathrm{L}^{-1} \mathrm{~L}$-glutamine, $1.74 \mu \mathrm{M} 6$ bencilaminopurine $(\mathrm{BAP}), 5.7 \mu \mathrm{M}$ indol-3-acetic acid (IAA) and 30 g.L - $^{-1}$ sucrose (Gomez-Kosky et al., 2000).

In the case of the chemical sterilization, Vitrofural ${ }^{\circledR}$ was added at a concentration of $114.0 \mathrm{mg} \cdot \mathrm{L}^{-1}$ to the culture medium previously dissolved with the agar and without autoclaving. All the culture vessels used in the chemical sterilization with Vitrofural@ were previously rinsed in a solution of sodium hypochlorite at $0.05 \%(\mathrm{v} / \mathrm{v})$. Once the culture medium and Vitrofural ${ }^{\circledR}$ were added to the culture vessel, there was a waiting period of three days before the somatic embryos were placed in them.

Ten groups of somatic embryos were used per treatment, and each group was comprised of 4-5 somatic embryos in the globular stage (Figure $2 \mathrm{~A}$ y $2 \mathrm{~B}$ ). Twenty culture vessels were used per treatment. The culture conditions were total darkness and a temperature of $25 \pm 2^{\circ} \mathrm{C}$.

The evaluations of the total number of somatic embryos formed were done at 15 and 20 days of culture. To evaluate the number of somatic embryos, 20 groups were randomly selected from each treatment and each group was added to a beaker $\left(50 \mathrm{~mL}\right.$ capacity), which contained $30 \mathrm{ml}$ of a solution of Gelrite ${ }^{\circledR}$ (Duchefa Co.) $\left(2.5 \mathrm{~g} \cdot \mathrm{L}^{-1}\right)$ and water. Thereafter, the content was spread in a Petri dish of $70 \mathrm{~mm}$ diameter. Counting of the somatic embryos was done with the aid of a stereoscope microscope - model WILD M8 (LEICA).

\section{Maturation and Germination}

One sample of secondary somatic embryos were subcultured to maturation medium according (Gomez-Kosky et al., 2000) during 25 days in the darkness condition. The germination of embryos was performed on M4 medium: MS medium, vitamins according to Morel and Wetmore (1951), $0.2 \mu \mathrm{M}$ BAP, $1.1 \mu$ Mindoleacetic acid, $30 \mathrm{~g} . \mathrm{L}^{-1}$ sucrose and 2 g.L ${ }^{1}$ Gelrite ${ }^{\circledR}$. The vessel culture were placed under artificial light conditions with a photoperiod of 16 hours of light, a temperature of $25 \pm 2{ }^{\circ} \mathrm{C}$ and photosynthetic photon flow density of $42-48 \mu \mathrm{mol} . \mathrm{m}^{-2} . \mathrm{s}^{-1}$ using fluorescent tubes light.

\section{Statistical Analysis of the Data}

The experimental designed used was completely randomized. The experimental data were processed using the nonparametric test Kruskal-Wallis. The means comparison was done according to the non-parametric test of Mann Whitney with a level of significance of $p \leq 0.05$.

\section{RESULTS}

The greatest secondary multiplication of banana somatic embryos was obtained in treatment 1 (glass culture vessel with plastic cover and sterilization in the autoclave) with a significant difference $(P \geq 0.05)$ with the rest of the treatments. In this treatment, mean values of 40.25 and $80.15 \pm 5.0$ somatic embryos per group were obtained at 15 and 20 days of culture respectively (Figure $2 \mathrm{C}$ and Figure 3). The multiplication coefficients were approximately 10 and 20 at 15 and 20 days of culture respectively for this treatment. One possible explanation to this result is related directly with the microenvironment inside the culture vessel. In the case of the glass culture vessel with plastic cover where the best results were obtained these had a lower volume of gaseous component $(220 \mathrm{~mL})$, but with ventilated exchange, which permits a greater renewal of the atmosphere inside the vessel (Table 1).

The smallest values of multiplication of somatic embryos were obtained in treatments 2 and 4 (Figure 2D and Figure 3), which used plastic culture vessel with less ventilation. This type of culture vessel, despite having a greater internal gaseous volume, had less ventilation (Table 1), which directly influenced the decrease in the multiplication coefficient of the banana somatic embryos with respect to treatment 1, with values of 16.4 and 17.3 respectively at 20 days of culture, with high synchrony of somatic embryos. Besides the internal microenvironment by the types of covers, it provokes water condensation on the walls of the culture vessel, raising the internal relative humidity to $98 \%$ (Figure $2 \mathrm{~B}$ ) and elevating the temperature by $1.5^{\circ} \mathrm{C}$ besides the fact that the culture was kept in darkness. In the case of the glass culture vessel with plastic cover, the internal temperature was $26.6^{\circ} \mathrm{C}$ with only a difference of $0.5^{\circ} \mathrm{C}$ with respect to the external temperature and the internal relative humidity of $80 \%$ (Table 2). All these factors played a role in the results obtained in this work.

It's important to highlight the lower results for treatment 3 (glass culture vessel with plastic cover and chemical sterilization) with respect to treatment 1 (Figure 3) with significant difference between them. Despite using the same 
culture vessel, it could have been due to the stress on the somatic embryos at the start of culture due to the presence of Vitrofural@ in the culture medium.

The amount of somatic embryos formed again in repetitive embryogenesis allows the use of secondary embryogenesis in the banana cultivar Grande naine (AAA) as an alternative to increase the number of somatic embryos in a short time, despite using semisolid culture medium, which can be an economically feasible variant for commercial laboratories. Cell suspensions can be used for continued multiplication in liquid culture medium and thereafter using a smaller amount of these to obtain somatic embryos in semisolid culture medium, which subsequently can be multiplied during several subcultures by secondary embryogenesis and this would make the process more efficient.

On analyzing the results in the stage of somatic embryogenesis in the different treatments, it is noted that at 15 days of culture there were no differences in the percentage of somatic embryos that were in the globular stage (98-100\%). However, at 20 days of culture, a greater number of somatic embryos in the scutellar stage started to appear (Figure 4). In the treatment ( 1 and 3 ) where glass vessels with plastic covers (ventilated) were used, the percentages of somatic embryos that remained in the globular stage were greater (70-78\%) compared to treatments 2 and 4 with the use of plastic vessel $(65-63 \%)$. These results support what was previously mentioned, with respect to the influence of the type of exchange in each culture vessel on secondary multiplication of somatic embryos. In this case, the ventilated culture vesse should present greater levels of oxygen, which made the presence of somatic embryos in the scutellar stage less and the somatic embryos in the globular stage greater

Somatic embryos in the culture medium for maturation achieving good development (figure $5 \mathrm{~A}$ ) after 25 days of culture in the same. This had a direct effect on subsequent germination in plant embryos. The values were reached between $80-$ $85 \%$ (Figure 5B).

\section{DISCUSSION}

Sinta et al. (2011) found that the use of different covers on the culture vessel for the micropropagation of oil palm (Elaeis guineensis Jacq.) affected the microenvironment inside the culture vessel. For banana and specifically somatic embryogenesis, there are no reports in the literature consulted.

In the case of somatic embryogenesis in the species Hevea brasiliensis, Auboiron et al. (1990) reported that the aeration in the culture vessel stimulated the differentiation of cells from the callus, and also the process of somatic embryogenesis. The absence of gases like $\mathrm{C} 2 \mathrm{H} 4$ and $\mathrm{CO} 2$ can be considered the main factors in the expression of somatic embryogenesis in callus of Hevea.

Several researchers have reported on the high relative humidity inside the culture vessel in the micropropagation of different species, which has caused physiological and anatomical disorders of shoots and plants (Ziv, 1990; Ghashghaie et al., 1992). Sinta et al. (2011) stated that the use of different covers on the culture vessel affected the microenvironment inside the vessel, the volume of the remaining culture medium, and the growth of the plants. The covers, depending on the type, increased the temperature by $1.6-2.6^{\circ} \mathrm{C}$ and decreased the light intensity by $1.7-8.7 \mu \mathrm{mol} / \mathrm{m}^{-2} / \mathrm{sec}^{-1}$ inside the culture vessels. Culture vessels with aluminum foil cover had the lowest temperature $\left(28 .{ }^{\circ} \mathrm{C}\right)$ and the lowest light intensity $\left(10.8 \mu \mathrm{mol} / \mathrm{m}^{-2} / \mathrm{sec}^{-1}\right)$ and gave the best results in the growth of oil palm plants (ElaeisguineensisJacq.).

It is known that high levels of oxygen promote secondary multiplication of somatic embryos and low levels stimulate histodifferentiation (Barbón-Rodriguez et al., 2008). In the glass culture vessels with greater ventilation, there is a greater growth rate, hence a greater increase in embryogenic cells, which imply greater formation of somatic embryos in the globular stage.

In banana, Braziliandwarf cultivar (Musa spp. AAB) Khalil et al. (2002) reported a culture medium for multiplication of secondary somatic embryos. The culture medium consisted of MS salts, $30 \mathrm{~g} . \mathrm{L}^{-1}$ sucrose and $10 \%$ coconut water however despite achieving repetitive embryogenesis had high asynchrony of embryos after two subcultures some somatic embryos reverted to callus. All this did not happen in the present work, in addition to the culture medium a mixture of two growth regulators known composition and concentration, contrary to use coconut water as a supplement, concentration of growth regulators used may vary by state of fruit maturity.

Remakanthan et al. (2014) report a simpler and faster for the development of somatic embryogenesis in banana cv. Grande naine protocol. However, these authors did not develop the phase of secondary somatic embryogenesis as part of their protocol, using picloram (synthetic auxin with high power auxin) for the formation of embryos somatic and finally having a very low germination (2-3\%) of somatic embryos at much lower levels than those obtained in this work, in the same banana cultivar.

In the case of the banana hybrid cultivar FHIA-18 (AAAB) and using bioreactors, Gomez-Kosky et al. (2002) obtained results showing that an elevated concentration of $\mathrm{DO}_{2}(80 \%)$ had the greatest proportion of globular somatic embryos, which produced at the end of culture 48,767 somatic embryos per liter. This amount represented $71.6 \%$ of the total, while $13.3 \%$ corresponded to mature somatic embryos. With a concentration of $40 \% \mathrm{DO}_{2}$ studied after 7 days of culture, the number of mature somatic embryos increased (31.3\%) and the globular stage somatic embryos decreased (47.1\%). This could be because in the maturation stage of somatic embryogenesis, there is decline in the growth rate, which made the metabolic activity focus on the process of differentiation, hence the somatic embryos start a process of accumulation of reserved substances and the physiological - morphological development necessary to reach maturation.

Mavituna and Buyukalaca (1996) worked with somatic embryogenesis in sweet pepper (Capsicum annuum cv. Ace), and pointed out that the consumption of oxygen is greatest in the initial stages of multiplication when compared to the 
maturation of somatic embryo. Also Barbón-Rodriguez et al. (2008), in embryogenic cell suspensions of Coffea arabica L. $\mathrm{cv}$. Red Caturra, obtained results that showed that the culture vessel with passive ventilation had greater number of somatic embryos in the globular stage with respect to the control with forced ventilation.

\section{CONCLUSIONS}

It is demonstrate that the glass culture vessel and the use of the autoclave had a positive response and superior secondary multiplication of banana somatic embryos starting from 15 days of culture. The importance of the covers on the internal atmosphere for the secondary multiplication of the somatic embryos was evident.

\section{REFERENCES}

[1] Auboiron, E., Carron, M-P., Michaux-Ferriere, N.1990. Influence of atmospheric gases, particularly ethylene, on somatic embryogenesis of Heveabrasiliensis. Plant Cell, T. Org.Cult. 21 (2):31-37.

[2] Agramonte, D., Jiménez, F.A., Pérez, M., Gutiérrez, O., Ramírez, D., Pérez, J., Alvarado, Y.1997. Empleo de sustancias de acción antimicrobianas en la esterilización de los medios de cultivo en la micropropagación in vitro de la papa (Solanum tuberosum L.). En: Técnicas de Avanzada Aplicadas a la Propagación Masiva de Plantas BIOVEG'97. Abstractbook. Ciego de Ávila, Cuba.p.161

[3] Barbón-Rodríguez, R., Jiménez, E., Preil, W. 2008. Influence of in vitro environment on somatic emryogenesis of Coffeaarábica L. cv. Caturrarojo: the effects of carbon dioxide on embryogenic cell suspensions. Plant Cell T. Org. Cult. 95 (3):155-161.

[4] Barry-Etienne, D., Bertrand, B., Schlonvoigt, A., Etienne, H.2002. The morphological variability within a population of coffee somatic embryos produced in a bioreactor affects them regeneration and the development of plants in the nursery. Plant Cell T. Org. Cult. 68 (2): 153-162.

[5] Berardi, G. and Marino, G. 1998. Growth and gas evolution in embryogenic cultures of Cyclamen persicum Mill. affected by the type closure. Adv. Hort. Sci. 12 (1): 19-24.

[6] Blondeau, J.M., Castañedo, N., González, O., Medina, R., Silveira, E.1999. In vitro evaluation of G-1: a novel antimicrobial compound. Int. J. of Antimicrobial Agents; 11(2): 163-166.

[7] Duetz, D.J., Witholt, B.2004.Oxygen transfer by orbital shaking of square vessels and deep well microliter plates of various dimensions. Biochem. Eng. J. 17 (3): 181-185.

[8] Celestino, C., Hernández, I., Carneros, E., López-Vela, D., Toribio, M.2005. La embriogénesis somática como elemento central de la biotecnología forestal. InvestAgrar: SistRecur For.;14 (3): 345-357.

[9] Chen, C.2004. Humidity in plant tissue culture vessels. Biosystems Engineering 88 (2): 231-241.

[10] Escalant, J.V., Teisson, C., Cote, F.1994. Amplified somatic embryogenesis from male flowers of triploid banana and plantain cultivars (Musa spp.). In vitro Cell. Dev. Biol-Plant 30 (2):181-186.

[11] FAOSTAT.citado 28 Jun 2013.Disponible en: http//www.faostat.fao.org/site/567/desktopdefault..

[12] Ghashghaie, J., Brenckmann, F., Saugier, B.1992. Water relations and growth of rose plants cultured in vitro under various relative humidities. Plant Cell T. Org. Cult.30 (3):51-57.

[13] Gómez-Kosky, R., Gilliard, T., Barranco, L.A., Reyes, M.V.2000.Somatic embryogenesis in liquid media. Maturation and enhancement of germination of the hybrid cultivar FHIA-18 (AAAB). InfoMusa19(1): 12-15.

[14] Gómez-Kosky, R., De Feria, M., Pérez, L.P., Gilliard, T., Martínez, F.B., Reyes, M.V., Milian, R.C., Quiala, E. 2002. Somatic embryogenesis of the banana hybrid cultivar FHIA-18 (AAAB) in liquid medium and scaled up in a bioreactor. Plant Cell T. Organ Cult.; 68 (2): 21-26.

[15] Huang, Ch and Chen, Ch.2005. Physical properties of culture vessels for plant tissue culture. Biosys. Eng. 91: 501-511.

[16] Jeong, C.S., Chakrabarty, D., Hahn, E.J., Lee, H.L., Pack, K.Y.2006. Effects of oxygen, carbon dioxide and ethylene on growth and bioactive compound production in bioreactor culture of ginseng adventitious roots. Biochem Eng. J. 27: 252-263.

[17] Khalil, S.M., Cheah, K.T., Pérez, E.A., Gaskill, D.A., Hu, J.S.2002. Regeneration of banana (Musa spp. AAB cv. Dwarf Brazilian) via secondary somatic embryogenesis. Plant Cell Reports 20:1128-1134.

[18] Lowe, K.C., Anthony, P., Power, J.B., Davey, M.R.2003. Novel approaches for regulating gas supply to plant systems in vitro: Application and benefits of artificial gas carriers. In Vitro Cell Dev. Biol.-Plant 39 (1): 557-566.

[19] Mavituna, F. and Buyukalaca, S.1996. Somatic embryogenesis of pepper in bioreactors: a study of bioreactor type and oxygen-uptake rates. Applied Microbio. and Biotech. 46 (4): 327-333.

[20] Morel, G. and Wetmore, R.H. 1951.Tissue culture of monocotyledons. Am. J. Bot. 38:138-140.

[21] Murashige, T. andSkoog, F.1962. A revised medium for rapid growth and bioassays with tobacco tissue cultures. Physiol. Plant.15: 473-497.

[22] Remakanthan, A., Menon, T.,Soniya,G. 2014. Somatic embryogenesis in banana (Musa acuminate AAA cv. Grande naine): effect of explant and culture conditions. In vitro Cell Dev. Biol.-Plant 50 (1): 127-136.

[23] Schenk. R.U., Hildebrandt, A.C.1972. Medium and techniques for induction and growth of monocotyledonous and dicotyledonous plant cell culture. Canad. J. of Botany 50: 199-204.

[24] Sinta, M., Riyadi, M., Sumaryono, I.2011.Effect of different culture vessel closures on the growth of oil palm (ElaeisguineensisJacq.) plantlets. Menara Perkebunan 79 (1): 15-22.

[25] Tisserat. B., Silman, R.2000.Interactions of culture vessels, media volume, culture density, and carbon dioxide levels on lettuce and spearmint shoot growth in vitro. Plant Cell Reports 19 (3): 464-471.

[26] Tonon, G., Berardi, G., Rossi, C., Bagnaresi, U.2001. Synchronized somatic embryo development in embryogenic suspensions of Fraxinus angustifolia. In Vitro Cell. Dev. Biol.-Plant 37 (4):462-465. 


\section{ISSN 2348-6201}

[27] Ziv, M.1990.Vitrification: morphological and physiological disorders of in vitro plants. En: Debergh, P.C., Zimmerman, R.H. editors. Micropropagation: Technology and Application, Kluwe Academic Publishers, Dordrecht, The Netherlands; p 45-69. 